\title{
Pregnancy in Adolescents in Mexico, Data versus Social Panic?
}

\author{
Noemi Ehrenfeld Lenkiewicz* \\ Department of Health Care, Universidad Autonoma Metropolitana-Xochimilco, Mexico
}

Submission: April 29, 2017; Published: May 25, 2017

*Corresponding author: Noemi Ehrenfeld Lenkiewicz, Department of Health Care, Universidad Autonoma Metropolitana-Xochimilco, Mexico, Email: enoe@xanum.uam.mx

\begin{abstract}
Adolescent pregnancy is a complex condition in which different social factors take part, such as economic living conditions, social background, and cultural issues concerning motherhood, education, and health outcomes of an early pregnancy. While public policies are directed to female population, there is no one official programme that addresses male sexuality and reproductive behaviours. Despite the statistics show a diminishing of specific fertility rate, there is a general social alarm strongly reinforced by the media in relation of adolescent pregnancy. Qualitative findings enrich statistical data, and show that in Mexican culture to become a mother is the most desirable condition for women, as adolescents report. Meanwhile, sexual activity before marriage or being single, pregnant or already an adolescent mother is still morally condemned by society. Different comprehensive policies should be designed and implemented in order to strongly support education attendance of adolescent women.
\end{abstract}

Keywords: Adolescent pregnancy; Official data; Social panic; Women’s voices; Seductive coercion

\section{Introduction}

Within most societies adolescent pregnancy is frequently constructed as a problem, and this is certainly the case in Mexico, where it has become a major social concern over almost the last three decades. However, the perspective on adolescent pregnancy is generally that of various states and religious agencies (health and educational institutions, welfare agencies and the church). Adolescent pregnancy is discussed in order to support arguments to explain the strong negative accent with which some social sectors address the topic, compared to women's own perceptions. For marginal urban adolescent culture, pregnancy and motherhood are distinct stages with different meanings. While pregnancy is an unintended condition at this moment of their lives, motherhood is also the most valuable status a woman can reach in this society [1].

Different factors confirm the mosaic of pregnancy in adolescents and structural causes of social nature, cultural mores, economic backgrounds and individual conditions can be identified. As a result all together may be involved in early motherhood. Among them, the lack of educational opportunities -that affect especially the future full development of these women- as a result in lower educational attainment is a clear problem in Mexican society. In 2010, 41 per cent of mothers between 12 and 19 years old had not completed their basic education [2].

Statistics concerning teenage pregnancy, adolescent mothers and fertility rate present some difficulties because the sources are not comparable in terms of the methodology employed. However, there are some relevant data that give account and enrich the discussion concerning specific fertility rate, especially if it has increased or decreased in the last ten years. ENADID (National Survey on Demographic Dynamics in Spanish abbreviation) show that between 2009 and 2014 birth per thousand adolescents aged 15 to 19 , increased about 10 percent [3]. These data elicited alarm in the media, with all kind of comments, citations and miss-interpretations, and some with extreme moral condemn that point to adolescents and lacking responsibility and thereby they become pregnant. In brief, these young women are guilty for their 'lack of care' of their sexual and reproductive behavior. When the group of adolescents 15-19 was studied in three different age subgroups (12-14, 15-17 and 1819), Mier y Teran Rocha \& Llanes Diaz [4] show that fertility of these groups differ substantially and that the increase in fertility rate is only clearly visible in the group 18-19 years old. 


\section{Global Journal of Reproductive Medicine}

The Government also reacted and in 2015 launched the National Strategy to Prevent Pregnancies in Adolescents [5] that seeks to reduce in 50 per cent the Specific Fertility Rate in women 15-19 years old. Considering the current trend of a slow decrease of specific fertility rate, it seems that this goal will not be achieved.

The adolescent women often face their pregnancies with contradictory feelings, but the idea that to become a mother is the best that can happen a woman is common amongst these women. They are trapped in a traditional social morality which asks them not to engage in premarital sex, but also demands and almost compels women to become mothers. Thus, to be pregnant is an intermediate status between being adolescent girls who are out of school, out of the labour market, with poor family emotional support, and belonging to poor marginal sectors of the society; and the promise of obtaining a better social status through becoming mothers. Pregnancy may therefore be seen as a problem because it highlights many factors that affect their lives and behaviours within large sectors of Mexican society. For example, material poverty and lack of education restrict these women, but pregnancy may also be the chance to move to the better and desirable status of motherhood.

The meaning of pregnancy for adolescents differs significantly from its meaning for other social actors and for relevant institutions. In the wider society, pregnancy in adolescents is still seen as a moral, educational and social problem, whilst these adolescents recognized that in Mexican society it is a way to raise their status within their families and social milieu, as well as to become real women, leading to greater social and cultural mobility and acceptability. Their accounts in pregnancy indicated both the difficulty they encountered in becoming pregnant before they were expect to (particularly if they were not married) and the advantages that could result from the enhanced status motherhood entails. Adolescent women are trapped by the official discourses that condemn adolescent pregnancy. They are also subject to the control of men through a seductive coercion and a culture that still emphasizes having children and building a family as the most desirable outcome for women. Most of the research in Mexico, as in other Latin American countries, most of the literature about pregnancy in adolescence emphasises clinical, epidemiological, demographic and medical views. These authorities privilege the relationship between health and adolescence, ignoring the existence of distinct cultural and social groups, and therefore cultural diversity and social and historical perspectives. However, there are few research that give relevance to adolescent women voices, what are their experiences and perceptions of sexual activity, of their pregnancy ad their expectations as young mothers. Little research has been done in Mexico working directly with subjects, in their own environment and collecting first-hand accounts of their experience and social context. Anthropological approaches, by contrast, often give full descriptions and details of a few issues related to pregnancy in adolescence, such as courtship [6]. But there are no studies that focus on the topic as a whole, not even in marginal Indian rural groups, which is one of the most frequent topics of study of this discipline in Mexico In fact, quantitative research do not allow an insight of the meanings of this event, but qualitative research enriches the understanding of this complex condition. Studies that emphasize qualitative methodology [1,7], enlighten important aspects concerning the contexts of pregnant adolescents and the last author will provide in this paper some information obtained from an research based on semi-structured interviews and material obtained from focus groups. Despite this work has been made years ago, some findings are still present currently and will be discussed.

\section{Material; Methods and Discussion}

Detailed semi structured interviews to 150 young pregnant women, aged 20 and younger, who attended a public hospital for their prenatal consultation being the youngest 12 years old were done. They were facing their first pregnancy, with the exception of 22 (15\%) who faced their second pregnancy and 2 (almost $3 \%$ ) who were experiencing their third pregnancy. Four focus groups were also conducted, where adolescents discussed about different topics related with their current pregnancies. 67 percent of the adolescents were living with their partners at the moment of the interviews, whether married or in cohabitation; three out of ten young women were told by their partners: I want us to have a child and about seven, I want you to give me a child. All of them were told how attractive they were to boys and that they wanted to have a family with them. Girls in this sample seem to be trapped in a seductive-coercion game; if they refuse to have sex, they lose their love. If they agree to have sex they change their status to another potentially higher emotional and social status, that of a mother. It is a tempting proposition considering their poor living conditions with no opportunities for education or a good job. At this time, 40 per cent of sample girls had not finished basic education and 30 per cent have finished the complete middle school, but only 15 per cent were still attending school. They became pregnant while being already out of school.

The relation between education, use of contraception at the first sexual relationship, age of first sexual relation and unintended (or not) pregnancy is a complex one. In 2014, 54.8 per cent of adolescents 15-19 years old, used some contraceptive protection at their first sexual relationship and 91 per cent used condom. Unintended pregnancy is about 18.5 per cent among those girls with the lower education (elementary school), however, adolescents that already have middle school or more, still have 21.9 per cent of unintended pregnancies, despite their better knowledge of contraception and of their own body [8].

The bulk of statistic information about the socio- demographic characteristics of adolescent population, their behaviour and tendencies concerning fertility rate, age start of sexual activity, use of contraception, educational level, work and education possibilities and realities, as well as the potential outcomes in 
terms of desire of a child, unintended pregnancy or undesired pregnancies in adolescents is enormous. Miss interpretations are also quite often present in the media, but it is also visible the alarm that they stress with the information available. It seems that social problems in relation with education, jobseeking ad lack of opportunities, social welfare policies are due to adolescent women, who get pregnant. There is no mention about male participation in these events, and there is also an absence of any specific official programme that addresses young men sexuality and reproductive behaviour. Media also points adolescent pregnancy as a result of the loss of moral bases of the Mexican family, due to the early practices of sexual activities by young women!

\section{Conclusion}

While pregnancy in adolescents is not addressed in a comprehensive condition, giving voice to young women, informing and making available their reproductive rights, supporting strong education policies to allow young mothers to continue their education and become more empowered, less dependent of a male culture that subordinate young women to male's will of "having a child" just to have access to sexual practices with their girls, specific fertility rates of adolescent population will diminish slower than desired by public policy makers. But pregnant adolescent women will continue facing difficulties in improve their individual and social conditions and so will probably their children.

\section{References}

1. Noemi EL (2011) Pregnancy in Mexican adolescents, redefining experiences, Sexuality, reproductive health and public policies: the voices of adolescents. LAMBERT Academic Publishing, Saarbrücken, Germany, pp 291

2. Arceo-Gómez Eva O, Raymundo MCV (2014) Teenage Prenancy in Mexico: Evolution and Consequences. LAJE 51(1): 109-146.

3. National Population Council (CONAPO) National Institute of Statistics and Geography (INEGI) (2015) National Survey of Demographic Dynamics 2014. Press Bulletin 27.

4. Rocha MYT, Marta, Nathaly LD (2017) The fecundity of Mexican adolescents: increasing or decreasing gradually? Demographic Situation, Mexico, pp: 35-42.

5. http://www.gob.mx/cms/uploads/attachment/file/55979/ ENAPEA_0215.pdf

6. Rodríguez G, De Keijzer B (2002) La noche se hizo para los hombres. Sexualidad en los procesos de cortejo entre jóvenes campesinos y campesinas, Libros para todos, S A de CV, Population Council, México, p. 250.

7. Stern, Claudio (2012) El problema del embarazo en la adolescencia. Contribuciones a un debate. El Colegio de México, p. 483.

8. CONAPO, (Consejo Nacional de Población) (2016) Situación de la salud sexual y reproductiva. República Mexicana, pp. 227.
This work is licensed under Creative Commons Attribution 4.0 Licens

DOI: 10.19080/GJORM.2017.01.555562
Your next submission with Juniper Publishers will reach you the below assets

- Quality Editorial service

- Swift Peer Review

- Reprints availability

- E-prints Service

- Manuscript Podcast for convenient understanding

- Global attainment for your research

- Manuscript accessibility in different formats

( Pdf, E-pub, Full Text, Audio)

- Unceasing customer service

Track the below URL for one-step submission https://juniperpublishers.com/online-submission.php 